\title{
The 26th ASME annual conference on information storage and processing systems, Santa Clara, CA, USA
}

\author{
Kyoung-Su Park ${ }^{1}$
}

Published online: 19 August 2017

(C) Springer-Verlag GmbH Germany 2017

It was our great honor and pleasure to host the 26th ASME annual conference on information storage and processing systems (ISPS 2016) at Santa Clara Marriott Hotel, Santa Clara, CA, USA from June 20 to June 21, 2016. The ISPS 2016 conference was co-located with the ASME IoT Connect (IoT) conference and InterPACK Workshop (IPW) this year. This joint events brought together manufactures, hardware R\&D, communications specialists, and business leaders to explore IoT hardware, from sensors and data storage devices to the system level.

In recognition of the emergence of the internet of things and its potential impact on data storage and processing, this year's conference theme focused on the new technology trends in data storage devices that support IoT and big-data analysis.

ISPS 2016 continued to offer an outstanding platform for researchers from both academic and industry to present their latest research progresses, exchange ideas and explore collaborate opportunities. The conference covered a wide spectrum of research topics that include all legacy ISPS technical area and a new technical session storage systems and future technologies to track the new trends arising from big data and data centers. Papers presented at the conference highlighted scientific and technological advancements in:

- tribology, head/media interface,

- actuator/suspension and sensors,

- servo control technology,

- shock and flow induced vibrations,

Kyoung-Su Park

Pks6348@gachon.ac.kr

11342 SeongnamDaero, 211 Engineering Blg \#2., Sujeong-Gu, Seongnam, Gyeonggi-do 461-701, Korea
- spindle motor and acoustics,

- micro/nano technology,

- mechatronics, robotics and automation,

- imaging/printing technologies and consumer electronics,

- opto-mechatronics and optical storage system,

- flexible media handling machines and printed electronics,

- storage systems and future technology.

ISPS 2016 had seen a good attendance and a balanced geographic and academic/industry mix in the audience. We had about 80 presentations covering the abovementioned areas in our 2-day conference. The conference featured one keynote presentation and one distinguished talk. At noon of the first day, we were pleased to have a keynote speech by Dr. Steve Campbell, Chief Technology Officer, Western Digital, on data storage technologies for IoT. At the ISPS banquet, the ISPS 2016 distinguished speaker Dr. Roger Wood, an HGST Fellow with Western Digital, delivered a speech on "The Superb Hard Disk Drive".

To facilitate easy reference in future, authors of presentations at the conference were invited to submit their full papers for consideration of publication in this special issue of microsystem technologies. All papers submitted went through a rigorous peer review process; many reviewers were leading experts in their areas of research and many of the papers had gone through a number of revisions before they were accepted for publication in the journal to ensure the quality of the journal. We would like to take this opportunity to express our sincerest gratitude to all our reviewers, who, despite their tight work schedule, have helped us review the papers in a timely manner on a voluntary basis. We would also reiterate our thanks to Prof. Bharat Bhushan and his colleagues at MST journal for the 
long time support for ISPS. Without their great efforts, this special issue of microsystems technologies would not be possible.

We would like to thank all authors, reviewers, organizers, ISPS EC members and ASME staff for supporting the ISPS 2016. Finally, we would like to thank all the participants in the conference, who are essential contributors to the success of this event.

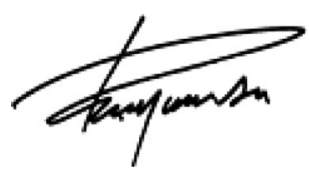

Prof. Kyoung-Su Park 